\title{
Cervical Thoracic Necrotizing Fasciitis with the Mammary Gland Spread of Odontogenic Origin
}

\author{
Seydou Togo ${ }^{*}$, Moussa Abdoulaye Ouattara1, Jaques Saye1, Ibrahim Boubacar Maiga1, \\ Cheick Ahmed Sékou Touré1, Ibrahim Sankaré1, Mamadou Abdoulaye Cheick Cissé2, \\ Nouhoum Diani' ${ }^{2}$, Sékou Koumaré ${ }^{3}$, Moussa Camara ${ }^{3}$, Adama Konoba Koita ${ }^{3}$, Sadio Yéna1, \\ Zimogo Zié Sanogo ${ }^{3}$, Djibril Sangaré ${ }^{3}$ \\ ${ }^{1}$ Department of Thoracic Surgery, Hospital of Mali, Bamako, Mali \\ ${ }^{2}$ Department of Reanimation and Emergency, Hospital of Mali, Bamako, Mali \\ ${ }^{3}$ Department of Surgery " $A$ ", Hospital of Point G, Bamako, Mali \\ Email: *drseydoutg@yahoo.fr
}

Received 13 March 2016; accepted 9 April 2016; published 12 April 2016

Copyright (C) 2016 by authors and Scientific Research Publishing Inc.

This work is licensed under the Creative Commons Attribution International License (CC BY).

http://creativecommons.org/licenses/by/4.0/

(c) (i) Open Access

\begin{abstract}
Necrotizing fasciitis is an uncommon infection, but potentially lethal, especially when associated with systemic disorders such as diabetes. We report the case of a 35-year-old female with uncontrolled diabetes mellitus, presenting with edema of the neck, facial and left mammary gland, secondary to untreated dental infection, progressing to a full-blown necrotizing fasciitis in a short period of time with sepsis. The patient was managed with aggressive multidisciplinary medical and surgical treatment. Despite the technologic advances in diagnosis and treatment, complications still result with astounding high mortality. Clearly, the morbidity associated to this infection, even in diabetic patients, can be minimized if an early diagnosis and effective debridement are done.
\end{abstract}

\section{Keywords}

Fasciitis, Necrotizing, Mammary Gland, Antibiotics, Surgery

\section{Introduction}

Cervical Thoracic Necrotizing Fasciitis (CTNF) with mammary gland spread is a rare and potentially fatal soft ${ }^{*}$ Corresponding author. 
tissue bacterial infection that affects female adult and elderly patients [1]. There are no reliable data on its true incidence in the population [2]. The origin is odontogenic in most cases, resulting from dental abscesses, chronic periodontal disease, or pharyngeal diseases. It progresses by forming extensive necrosis and gas in subcutaneous tissues and the underlying fascia, and has a mortality rate about $40 \%$ [2]. This disease is usually polymicrobial; untreated or rapidly spreading odontogenic infections can be potentially life threatening secondary to airway compromise or septicemia [3]. Risk factors for CTNF are uncontrolled diabetes mellitus, peripheral vascular disease, liver diseases, and immune diseases especially HIV [2]. Imaging is essential to define the topography of the infection. In our knowledge there are few reports in electronic literature highlighting CTNF with mammary gland spread from odontogenic origin [4]. Successful treatment requires an early diagnosis, radical surgical debridement of all necrotic tissues, intravenous broadspectrum antibiotic therapy, and aggressive general support measures. We present this case due to the clinical rarity and highlight the effective management strategy.

\section{Case Report}

A female patient aged 35 years with diabetes presented a facial cervical and the left mammary gland edema that suggested cellulitis, and a history of untreated dental infection. Subsequently, she was sent to our emergency department. On the physical examination, there was mandibular trismus, the submandibular, sublingual, and submental regions were enlarged, painful, and hardened; this extended to the left mammary gland (Figure 1). An oral examination showed teeth number 36, 37, 46 with caries and several remaining tooth roots. Hyperemia, hyperthermia (body temperature was $39.5^{\circ} \mathrm{C}$ ), tachypnea, dehydration, and leukocytosis indicated sepsis. Computed tomography showed characteristic subcutaneous emphysema and revealed the true extent of the infection to the mammary gland (Figure 2(a)). It identified the causal teeth with the submandibular abscess (Figure 2(b)). The patient was admitted in the intensive care unit and 48 hours after admission, the anterior neck and the left mammary gland were necrosed and exposed (Figure 3(a)). Emergency treatment was started, involving radical surgical debridement. Aggressive debridement of the neck was done; the procedure reached the mammary gland, the midpoint of the left clavicle, and the base of the mandible. Antibiotic therapy was started empirically with ceftriaxone, gentamycin and metronidazole. During surgery, material was taken and sent for culture and an antibiogram. Multiple causative bacteria were identified in neck pus such us Klebsiella pneumoniae and escherichia colli. The blood cultures showed two strains of bacteria: Serratia marcescens and staphylococcus saprophyticus. Antibiotic sensitivity testing showed that they were sensitive to the following antibiotics: amycacin, gentamycin, imipenem and cilastatin. The treatment was secondary adjusted according to the result of antibiogram. Treatment of the teeth was done by the dental surgeon. Additional smaller areas of the breast were debrided after, during the end of the second week. The patient was discharged 5 weeks after admission with good evolution of the lesions (Figure 3(b)). The patient was out of any complaint in the term of 3 months. Informed consent was obtained from the patient and the ethical committee for publication.

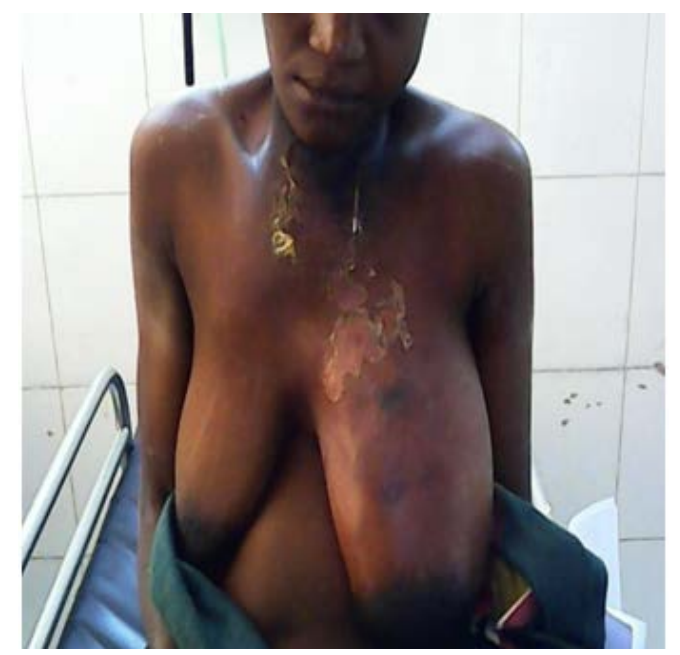

Figure 1. Facial and neck regions edema with enlarged left mammary gland. 


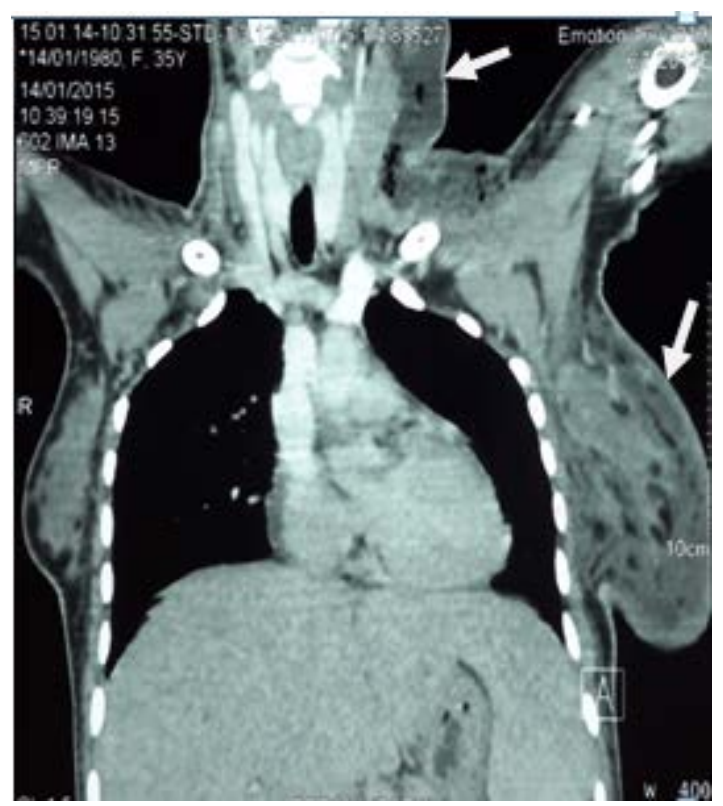

(a)

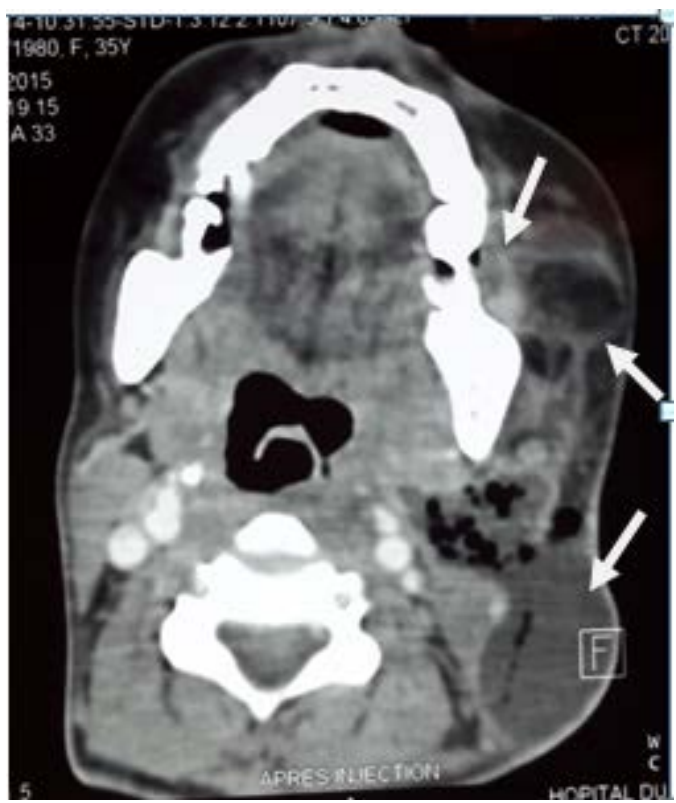

(b)

Figure 2. Computed tomography scan of the head, neck and thorax. (a) Cervical collection with subcutaneous emphysema of the left breast; (b) submandibular and peri-molar abscess.

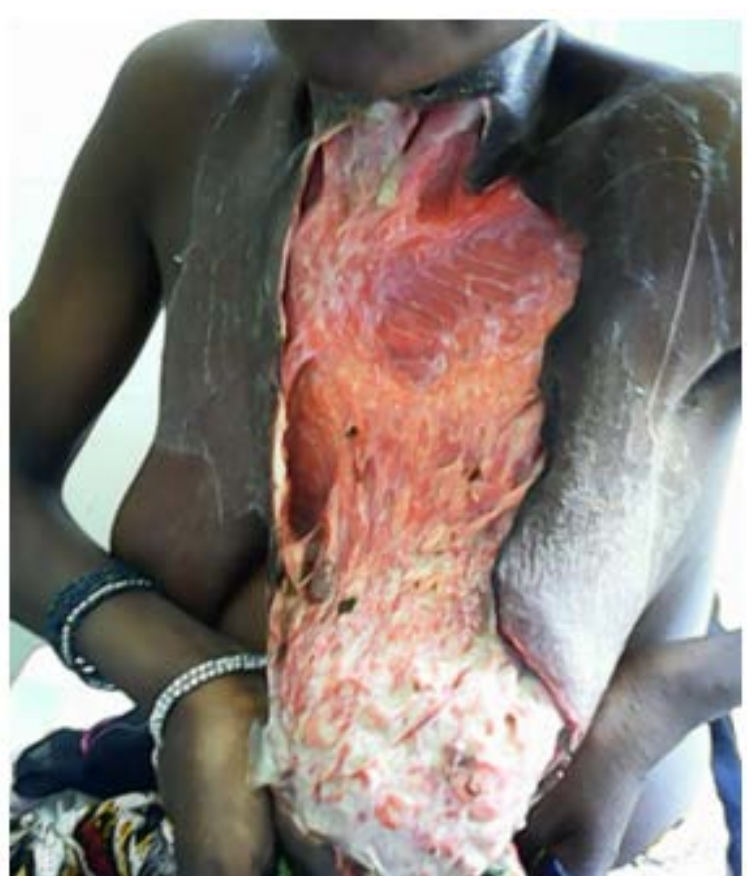

(a)

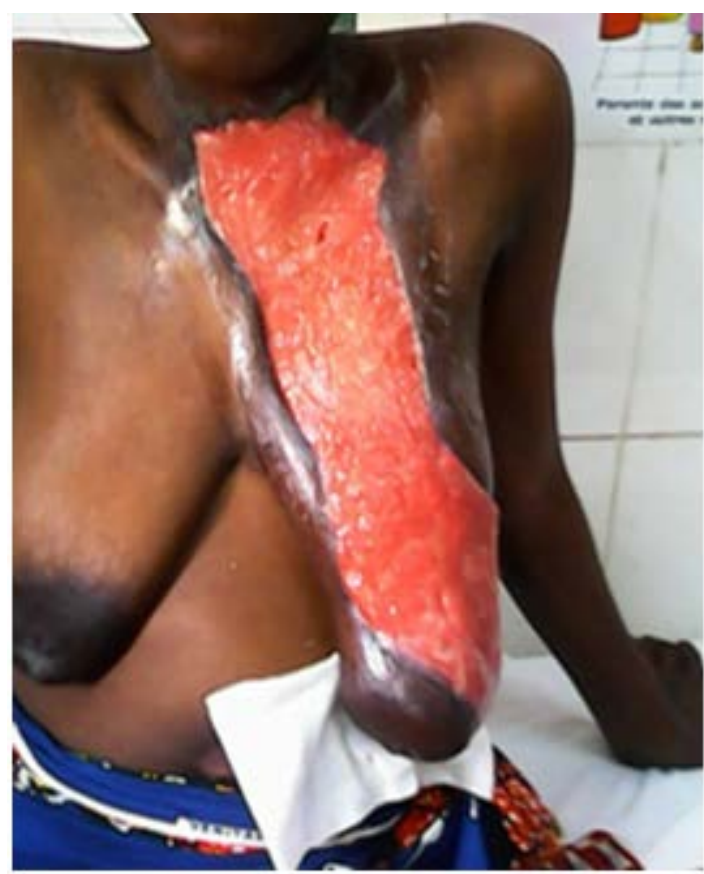

(b)

Figure 3. Evolution of necrotizing fasciitis. (a) Rapid necrosis of the mammary gland 48 hours after admission; (b) evolution after 5 weeks of treatment.

\section{Discussion}

This study presents a case of cervical thoracic necrotizing cellulitis with mammary gland spread of odontogenic origin in a patient with diabetes, which progressed rapidly to the neck and the left mammary gland. Authors reported that $81 \%$ of such cases start from the second or third inferior molars and at least one underlying disease 
was found in over $70 \%$ of patients with facial cervical cellulitis [5] [6]. In this case untreated diabetes was found. In the developed world, fatal dental infections are rare in patients with intact immune response [7] [8]. In the third world, where people are malnourished owing to poverty, fatalities are more common. Another possible contributory factor to poor outcome in the developing world is late presentation with consequent delayed surgical intervention. In addition, the use of herbal medication in our context delayed the diagnosis. Buccal space and submasseteric space infection represented $7.3 \%$ of all oral infection and sources of infections were of odontogenic origin in 92.7\% of cases in developing world [4]. The diagnosis of CTNF with mammary gland spread of odontogenic origin is essentially medical (based on non-elastic skin edema, hypoesthesia, subcutaneous crepitus, etc...). It is confirmed during surgery by noting poor adherence of subcutaneous tissues, lack of bleeding, and necrosis of the fascia. Emergency surgery was done after computed tomography showed characteristic subcutaneous emphysema and revealed the true extent of the infection to the mammary gland. Rapid necrosis of the neck and thoracic subcutaneous tissues was observed 3 days after admission [4] [6]. In our patient rapid necrosis was observed 48 hours after admission. The polymicrobial aspect in our patient led to rapid catastrophic consequences. The findings at surgery included a decreased resistance to dissection, necrosis in deeper layers of the fascia, necrosis of the skin and subcutaneous tissue, drainage of pus, and a fetid odor, which sealed the diagnosis of necrotizing fasciitis [9] [10]. Similar case reported with necrotising fascitis arising from untreated odontogenic infection showed that a finding of multiple causative bacteria was typical of the classic polymicrobial pattern of this infection and early antibiotic therapy associated with surgical debridement of all necrotic tissues is necessary to prevent considerable morbidity and mortality [4]. Antibiotic therapy was effective in this case. Adjuvant measures, such as immunoglobulins, hyperbaric oxygen therapy and cutaneous graft can also currently employed and will help for healing lesions but those measures were not used in this patient.

\section{Conclusion}

Rarely dental infection may cause severe mammary gland necrotizing. This condition progresses rapidly, especially when associated with predisposing factors. The treatment requires a prompt diagnosis, adapted antibiotic therapy and radical surgical debridement. Nowadays oral hygiene remains a serious problem of public health in this part of the world.

\section{References}

[1] Ord, R. and Coletti, D. (2009) Cervico-Facial Necrotizing Fasciitis. Oral Diseases, 15, 133-141. http://dx.doi.org/10.1111/j.1601-0825.2008.01496.x

[2] Kuncir, E.J., Tillou, A., St Hill, C.R., Petrone, P., Kimbrell, B. and Asensio, J.A. (2003) Necrotizing Soft-Tissue Infections. Emergency Medicine Clinics of North America, 21, 1075-1087. http://dx.doi.org/10.1016/S0733-8627(03)00089-0

[3] Rega, A.J., Aziz, S.R. and Ziccardi, V.B. (2006) Microbiology and Antibiotic Sensitivities of Head and Neck Space Infections of Odontogenic Origin. Journal of Oral and Maxillofacial Surgery, 64, 1377-1380. http://dx.doi.org/10.1016/j.joms.2006.05.023

[4] Otasowie, D.O., Benjamin, I.A., Akinwale, A.E. and Adetokunbo, R.A. (2012) Management of Fascial Space Infections in a Nigerian Teaching Hospital: A 4-Year Review. Nigerian Medical Journal, 53, 12-15. http://dx.doi.org/10.4103/0300-1652.99823

[5] Whitesides, L., Cotto-Cumba, C. and Myers, R.A. (2000) Cervical Necrotizing Fasciitis of Odontogenic Origin: A Case Report and Review of 12 Cases. Journal of Oral and Maxillofacial Surgery, 58, 144-151. http://dx.doi.org/10.1016/S0278-2391(00)90327-6

[6] Kaul, R., McGeer, A., Low, D.E., Green, K. and Schwartz, B. (1997) Population-Based Surveillance for Group A Streptococcal Necrotizing Fasciitis: Clinical Features, Prognostic Indicators, and Microbiologic Analysis of Seventy-Seven Cases. The American Journal of Medicine, 103, 18-24. http://dx.doi.org/10.1016/S0002-9343(97)00160-5

[7] English 2nd, W.J. and Kaiser, A.B. (1979) Lethal Toothache: Paraphyryngeal Cellulitis Complicating Dental Infection. Southern Medical Journal, 72, 687-689. http://dx.doi.org/10.1097/00007611-197906000-00016

[8] Heimdahl, A., von Konow, L., Satoh, T. and Nord, C.E. (1985) Clinical Appearance of Orofacial Infections of Odontogenic Origin in Relation Tomicrobiological Findings. Journal of Clinical Microbiology, 22, 299-302.

[9] Wolf, H. and Ovesen, T. (2008) Necrotizing Fasciitis in the Head and Neck Region. Ugeskrift for Lager, 170, $2563-2566$.

[10] Akinbami, B.O., Akadiri, O. and Gbuje, D.C. (2010) Spread of Odontogenic Infections in Port-Harcourt, Nigeria. Journal of Oral and Maxillofacial Surgery, 68, 2472-2477. http://dx.doi.org/10.1016/j.joms.2010.01.019 